\title{
Conchas aos montes: situando os montes artificiais de conchas nos estudos da pré-história brasileira e japonesa
}

\author{
Silvia Reis* \\ Claudia Rodrigues-Carvalho**
}

\begin{abstract}
REIS, S.; RODRIGUES-CARVALHO, C. Conchas aos montes: situando os montes artificiais de conchas nos estudos da pré-história brasileira e japonesa. R. Museu Arq. Etn., 28: 124-132, 2017.
\end{abstract}

Resumo: Sítios arqueológicos marcados pela aparente presença de conchas, nomeados assim por sua característica mais visível, podem ser encontrados em diferentes regiões do mundo. No Brasil, conhecidos principalmente como sambaqui, e no Japão como kaizuka, os estudos de tais montes de conchas estão inseridos em questões locais, regionais e mundiais. Assim, buscamos situar os estudos de montes de conchas em relação aos questionamentos dos quais são objeto e, em uma perspectiva comparada, em que medida estão inseridos em linhas investigativas passíveis de diálogo.

Palavras-chave: Sambaqui; Kaizuka; Arqueologia brasileira; Arqueologia japonesa.

O silêncio não é o vazio, o sem-sentido; ao contrário, ele é o indício de uma totalidade significativa.

Isto nos leva à compreensão do "vazio" da linguagem como um horizonte e não como falta.

Eni Puccinelli Orlandi, As formas do silêncio

Sítios arqueológicos, vestígios de uma

história muitas vezes desconhecida, devem ser abordados tendo em vista seu entorno. Da paisagem à topografia, à contextualização cultural e sociopolítica, um sítio arqueológico também é construído no imaginário social e no campo científico. As muitas vidas da cultura material - codificada

* Museu Nacional. Universidade Federal do Rio de Janeiro. <s_breis@yahoo.com.br>

** Museu Nacional. Programa de Pós-Graduação em Arqueologia, Universidade Federal do Rio de Janeiro. <claudia@mn.ufri.br> socialmente em seu contexto original de produção, mas reapropriada e recodificada por nós - precisam ser colocadas em evidência. É necessário contextualizar a própria produção do conhecimento, em que meio se insere o remanescente transformado em objeto de estudo e quais os diálogos travados.

Tanto sambaquis quanto kaizuka são situados nos estudos de pré-história, produzidos principalmente por populações desconhecidas, aparentemente sem ligação direta com populações atuais. Todavia, enquanto sambaquis se encontram em meio a outras evidências entendidas como deixadas por outros grupos, kaizuka são entendidos como mais uma evidência, em meio a diversas outras, de um mesmo sistema cultural ou de populações sob uma identidade cultural agregadora. O contraste, assim, é visto em relação às populações provenientes da onda migratória 
posterior. Dessa forma, ambos são estudados em si e em contraste, no exercício antropológico por excelência, o método comparado.

\section{Situando sambaqui}

Prous (1992) localiza o início da arqueologia brasileira no período de 1870 a 1910, da construção e do enriquecimento das coleções do Museu Nacional, criado por D. João VI, ao embate das primeiras teorias sobre sambaqui. Nesse embate, transparece também a rivalidade entre o Museu Nacional e o Museu Paulista, respectivamente, se os sambaquis eram construções artificiais ou montes de formação natural.

Sambaqui, nome de origem tupi, referese a um amontoado de conchas, vindo de tamba, conchas, e ki, amontoado. Também são encontrados resquícios de peixes e mamíferos, vestígios de flora, como sementes, além de sepultamentos, material lítico e artefatos. $\mathrm{O}$ tamanho é variado e alguns podem chegar a mais de $30 \mathrm{~m}$ de altura, com a marcante presença de sepultamentos na maioria dos sambaquis encontrados.

A primeira questão levantada centravase na formação dos sambaquis, polarizada entre naturalistas e artificialistas. Dentre os naturalistas, destacava-se Hermann von Ihering, diretor do Museu Paulista, para o qual os sambaquis eram acúmulos naturais de conchas. Por parte dos artificialistas, destacavam-se os pesquisadores do Museu Nacional, dirigidos por Ladislau Netto, que mandou diversas missões para escavar sambaquis do litoral sul - os quais estavam sendo destruídos em vista da extração de conchas para fabricação de cal.

O embate entre tais polos teóricos estendeu-se até 1940. Com a exposição e análise dos indícios encontrados nas escavações, gradualmente os naturalistas foram concedendo diversos aspectos de seu corpo teórico, até por fim a questão ser fechada: os grandes sambaquis, com seus sepultamentos, artefatos, riqueza e complexidade, foram construídos sob ação humana intencional. Todavia, no decorrer desse processo, surge uma terceira vertente, mista, para a qual os sambaquis eram resultado de uma mistura de ação humana e ação natural, destacando-se como seu defensor RoquettePinto (Prous 1992).

Segundo Gaspar (2004: 13-14), a corrente artificialista pode ser subdividida em duas vertentes que continuam seus estudos até hoje no tocante à apropriação e significado dos sambaquis. Enquanto uma interpreta os sambaquis como resultado de descarte do que não era aproveitado para alimentação, implicando a ideia de moradia, a outra os interpreta como estruturas funerárias.

O grupo denominado como construtor de sambaquis era de caçadores-coletores-pescadores, e explorava tantos os recursos marinhos quanto os recursos do interior (Wesolowski et al. 2007). Por volta de mil sambaquis já foram catalogados, e estima-se que outros mais tenham sido destruídos durante a ocupação colonial do litoral. A datação mais antiga reconhecida é de aproximadamente 6.000 anos antes do presente, com algumas datações controversas chegando a 8.000 anos, e a mais recente de 2.000 anos.

Sobre alguns sambaquis, há ainda sítios de possivel identidade cultural diferente, de ocupação posterior, com camadas de composição diferenciada e com presença de cerâmica. Indaga-se em que medida seriam esses, em cada caso, oriundos de uma cultura diferente ou a continuação da mesma com a presença de novas técnicas (desenvolvimento ou troca).

Da mesma forma, conjuntos de sambaquis próximos uns dos outros são estudados com a perspectiva de possivel contemporaneidade entre eles, como um complexo sambaquieiro. A caracterização, assim, dos sítios e das respectivas populações pretéritas são investigadas tendo como viés a oposição litoral e interior, préceramistas e ceramistas. Segundo Prous (1992), pode-se simplificar a cronologia da pré-história brasileira contrapondo populações do Pleistoceno e Holoceno, e subdividindo o último em três períodos arcaicos:

$\mathrm{Na}$ arqueologia indígena, o estudo de cerâmica é uma das bases fundamentais para identificação e caracterização cultural, diferenciando grupos através de sua cultura 
Conchas aos montes: situando os montes artificiais de conchas nos estudos da pré-história brasileira e japonesa

R. Museu Arq. Etn., 28: 124-132, 2017.

material. Segundo Schiavetto (2005: 86), “a ideia de sociedade brasileira não exclui as especificidades étnico-culturais dos indígenas, mas sim, leva em consideração o seu papel fundamental na construção da identidade nacional”. O arqueólogo, assim, precisa produzir um discurso tanto local (étnico) quanto global (nacional), que ultrapasse a mera descrição e catalogação.

A heterogeneidade das culturas indígenas é de fato percebida e, diante dos grupos sambaquieiros, a principal distinção é a presença de cerâmica. As camadas em sambaquis com presença de cerâmica são entendidas de várias formas, mas principalmente como ocupação posterior indígena. Dessa forma, um mesmo sítio ganha caráter múltiplo com sobreposição de identidades culturais entendidas como distintas. Poucos sítios com presença de cerâmica em diversas camadas foram registrados, em sua maioria na região Norte, e relatados principalmente no século XIX (Penna 1876).

A própria definição e delimitação do que pode ser classificado como sambaqui é tênue. Há ainda termos associados, como sambaqui sujo (com mais terra do que conchas) e cerrito (monte de terra), com critérios não sedimentados para determinar sítios em situação de liminaridade, tendo-se como principal modelo comparativo os chamados sambaquis clássicos, indisputados em sua classificação na literatura da Arqueologia Brasileira (Prous 1992; Loureiro 2033).

No início dos estudos de pré-história, no século XIX e início do século XX, nota-se a distinção de três temas distintos: o chamado homem de Lagoa Santa, homem dos Sambaquis e grupos indígenas ainda vivos (Lacerda 1885; Peixoto 1885; Netto 1885). Dentro de uma perspectiva de hierarquização social e biológica, cada população, em cada um dos temas, foi estudada nesse período, buscando caracterizar e entender um passado entendido como selvagem e não civilizado.

Nesse viés, diversos autores, como João Batista de Lacerda, compararam sambaquieiros, remanescentes de Lagoa Santa e, principalmente, Botocudos, sendo estes muitas vezes entendidos como o grau mais inferior. As comparações realizadas buscavam relações e distinções e, em geral, chegavam a algum grau de proximidade, ora propondo os Botocudos como descendentes da população de Lagoa Santa, ora os sambaquieiros.

Em relação à migração e à mobilidade, no século XIX especulava-se a chegada de diversas ondas migratórias, de vikings a japoneses (ou uma população anterior à migração que originaria a população japonesa atual), influências das mais díspares, buscando explicar diferenças entre a cultura material encontrada em sítios arqueológicos e não mais produzida por populações recentes.

\begin{tabular}{|c|c|c|c|}
\hline & \multicolumn{2}{|c|}{ Pleistoceno } & $\begin{array}{l}\text { Remanescentes humanos. Lagoa Santa/MG, dentre } \\
\text { outros sítios de abrigos rochosos. Poucas informações. }\end{array}$ \\
\hline 12.000 & \multirow{3}{*}{ Holoceno } & Arcaico antigo & Sítios com características diferentes dos do Pleistoceno. \\
\hline 9.000 & & Arcaico médio & $\begin{array}{l}\text { Culturas em geral pré-ceramistas. Diversas tradições } \\
\text { indígenas no interior. Sambaquis de datação mais } \\
\text { antiga em São Paulo, por volta de } 8 \text { mil anos (Calippo } \\
\text { 2010), e no Baixo Amazonas, sítio Taperinha (Bandeira } \\
\text { 2006). }\end{array}$ \\
\hline 4.500 & & Arcaico recente & $\begin{array}{l}\text { Desenvolvimento de agricultura no interior. Culturas } \\
\text { em geral ceramistas. Diversas tradições indígenas tanto } \\
\text { no interior como no litoral. Sambaqui com datação } \\
\text { mais recente: } 2 \text { mil anos antes do presente. }\end{array}$ \\
\hline
\end{tabular}

Quadro 1. Cronologia simplificada da pré-história brasileira (AP).

Fonte: Elaborado pelas autoras com base em Prous 1992. 
Atualmente, a chegada ao continente americano e as subsequentes rotas migratórias continuam em pauta, mesmo com a hegemonia da perspectiva de entrada pelo Estreito de Bering. Discute-se ainda se a entrada no continente americano foi por meio de um evento único migratório (Raghavan 2015) ou se as populações seriam originárias de diferentes ondas migratórias (Skoglund 2015).

\section{Situando kaizuka}

O início da arqueologia científica no Japão é marcado pelos trabalhos de Edward Sylvester Morse (1838-1925), zoólogo americano que escavou um dos principais sítios Jomon, Omori, em Tóquio. Lecionou na Universidade de Tóquio de 1877 a 1879 e, de sua publicação sobre o kaizuka de Omori (Morse 1879), ao descrever a cerâmica encontrada, foi nomeada a Era Jomon. Morse descreveu tal cerâmica como "marcada por corda”, Jomon (縄文), uma vez que parte dos padrões encontrados parecia ser feita a partir da impressão de corda sobre a cerâmica ainda crua (Imamura 1996, 2000b).

No entanto, Mizoguchi (2006: 60) aponta que um dos principais arqueólogos japoneses da época, Tsuboi Shogoro (1863-1913), primeiro professor do Departamento de Antropologia da Universidade de Tóquio, negava a influência de Morse. Apesar do pioneirismo na escavação e análise de kaizuka, Morse de fato treinou e deixou apenas dois alunos, Isao Iijima (18611921) e Chujiro Sasaki (1857-1938), que escavaram e publicaram juntos sobre outro kaizuka, Okadaira (Sasaki \& Iijima 1880), localizado na prefeitura de Ibaraki. Também foram responsáveis pela tradução japonesa do artigo de Morse sobre Omori. Iijima tornouse um dos fundadores da Zoologia japonesa e Sasaki, da Entomologia (Imamura 2000a, 2000b).

O Paleolítico é caracterizado principalmente pelas conexões entre o arquipélago japonês e o continente asiático, que teriam possibilitado a entrada no território durante o Pleistoceno. O material osteológico humano de datação mais antiga é o proveniente dos sítios Minatogawa e Mikkabe, em Okinawa, de aproximadamente 18.000 anos antes do presente (Matsu'ura \& Kondo 2011).

A Era Jomon começaria por volta da época do isolamento do arquipélago, no início do Holoceno, quando as ligações com o continente desapareceram, e é subdividida em seis períodos (Quadro 2). Segundo Imamura (1996), o Paleolítico é geralmente entendido como período pré-cerâmico, mas evidências de cerâmica no final do Pleistoceno colocam em questão esse critério de classificação. Em geral, a Era Jomon é demarcada pelo advento da cerâmica até a introdução de agricultura, especialmente de arroz em campo irrigado.

A famosa cerâmica marcada por corda é encontrada em algumas regiões, ausente por um longo período em Kyushu e presente em algumas regiões durante a Era Yayoi, não sendo, assim, uma característica precisa do período. Imamura (1996) ainda aponta a ausência de agricultura ao longo dos cinco períodos como um dos impedimentos para caracterizar essa era como Neolítico, restando apenas Jomon como o termo mais apropriado.

De acordo com Habu (2004), até a década de 1990 arqueólogos desconfiavam da precisão da datação por carbono-14 $\left({ }^{14} \mathrm{C}\right)$, optando por privilegiar datações por tipos de cerâmica, com diversos tipos de subfase, e diferenciação de presença regional. Datas mediante ${ }^{14} \mathrm{C}$ só começaram a ganhar mais adeptos no início do século XXI. Nesse sentido, a fraude do Paleolítico, conduzida por Shin'ichi Fujimura, com datas de até 600 mil anos, colocou em dúvida todas as datações de sítios nos quais Fujimura atuou (Romey 2001; Hudson 2005).

$\mathrm{O}$ termo em japonês que designa monte de conchas é kaizuka (貝塚). O primeiro ideograma, kai, significa concha, e o segundo, tsuka, significa monte, morro pequeno, morro de sepultamento, túmulo. Com tamanhos variados, mas, em geral, sem ultrapassar cinco metros de altura, podem ser encontrados em dois tipos de formatos, circular e forma de ferradura. 
Conchas aos montes: situando os montes artificiais de conchas nos estudos da pré-história brasileira e japonesa R. Museu Arq. Etn., 28: 124-132, 2017.

\begin{tabular}{|c|c|l|}
\hline \pm 30.000 & Paleolítico & Material lítico e fogueiras \\
\hline \pm 3.000 & Jomon Incipiente & Pouca cerâmica, estilo simples. \\
\hline \pm 9.000 & Jomon Inicial & $\begin{array}{l}\text { Início da construção de kaizuka, de cerâmica com impressão de corda, e } \\
\text { maior diversidade de artefatos. }\end{array}$ \\
\hline \pm 6.000 & Jomon Anterior & $\begin{array}{l}\text { Período do aumento da temperatura e do nível do mar. Vários padrões } \\
\text { novos de cerâmica aparecem. }\end{array}$ \\
\hline \pm 4.000 & Jomon Médio & $\begin{array}{l}\text { Ápice da cultura Jomon e Ótimo Climático. Grande quantidade de } \\
\text { assentamentos, provavelmente de caráter sazonal. Cerâmica mais } \\
\text { elaborada. }\end{array}$ \\
\hline \pm 3.000 & Jomon Final & $\begin{array}{l}\text { Maior concentração de assentamentos no litoral, aumento de artefatos } \\
\text { rituais e sepultamentos. Novas técnicas de cerâmica. }\end{array}$ \\
\hline \pm 2.500 & $\begin{array}{l}\text { Maior concentração de sítios na região Nordeste. Cerâmica simples, } \\
\text { algumas laqueadas. Indícios de cultivo de plantas e entrada da } \\
\text { agricultura. }\end{array}$ \\
\hline
\end{tabular}

Quadro 2. Cronologia geral aproximada dos períodos da Era Jomon (+13.000 - 2.500 AP).

Fonte: Elaborado pelas autoras

Alguns kaizuka contam com a presença de sepultamentos e outras estruturas, não necessariamente como parte de sua construção, mas como evidências de diferentes momentos de ocupação e apropriação do mesmo espaço. Estão relacionados a um cenário amplo, dentro da questão da mobilidade, da apropriação do território, sedentarismo e recursos para alimentação.

A população da Era Jomon é caracterizada como caçadora-coletora-pescadora, com construção de assentamentos e vilas sazonais - há então a questão do grau de sedentarismo e nomadismo, uma vez que a maior parte dos recursos encontrados em sítios é proveniente de áreas próximas, apontando para a possibilidade de sedentarismo. No entanto, a diversidade e a especialização de certos assentamentos trazem a questão da sazonalidade de seu uso (Imamura 1996; Habu 2004; Kobayashi 2004).

Entre as diversas questões que permeiam as investigações arqueológicas, Mizoguchi (2002) evidencia a temática da homogeneidade do povo japonês: no imaginário do japonês médio, há a ideia de uma ancestralidade presente tanto no corpo de cada indivíduo quanto no corpo coletivo, na própria sociedade. Mizoguchi argumenta que tal imagem deriva do desenho do território, um arquipélago de certa maneira isolado e que, pelo decorrer da história conhecida, permaneceu, por assim dizer, "íntegro".

Assim, a noção de ancestralidade que se perde na origem de tempos imemoriais, aliada à crença de uma homogeneidade étnica (não reconhecendo diferenças na nação para além dos Ainu e da população da atual Okinawa), traria, frente aos remanescentes pré-históricos, o questionamento de como e em que medida estes se encaixam nesse discurso.

Mizoguchi (2002) aponta o trabalho de Sahara Makoto que, ao analisar remanescentes de um sítio arqueológico datado de aproximadamente 30.000 anos antes do presente (datação em carbono não calibrado), disse que se sentiu tentado a afirmar que os japoneses "sempre estiveram aqui". Dessa forma, em diversos trabalhos arqueológicos e de antropologia biológica, pesquisadores japoneses buscavam delimitar o início do corpo japonês de fato, diferenciando-o dos que antes habitaram o mesmo arquipélago, mas não se encaixariam nessa linhagem.

Assim, podemos encontrar diversos trabalhos de morfologia comparada, a fim de delimitar linhagens populacionais. Em uma 
série de artigos publicados por Yamaguchi Bin, do Departamento de Antropologia do Museu Nacional de Ciência, são abordadas as diferenças das medidas de ossos da mão (Yamaguchi 1990) e do pé (Yamaguchi 1991) de uma amostra de remanescentes do Jomon Tardio, provenientes de Ebishima, frente a populações modernas de japoneses e Ainu.

Yamaguchi chegou à conclusão de que, morfologicamente, tal série Jomon se aproximava mais dos Ainu modernos, uma vez que teriam ossos mais longos do que os atuais japoneses, enquanto os Ainu se encontrariam no meio dessa escala de comparação, um pouco mais longos que os últimos, sugerindo, para ele, a possibilidade de ligação entre os Ainu e os Jomon.

Segundo Mizoguchi (2006: 60), a história do Japão, desde a Restauração Meiji até o final da Segunda Guerra, pode ser entendida como um período de continua reproblematização da identidade nacional e da caracterização dos japoneses como população. Assim, o início da arqueologia no Japão é marcado pelos movimentos de fortalecimento da identidade nipônica diante do aumento da influência ocidental e da modernização, defendida por alguns e combatida por outros. A integridade da trajetória japonesa na história e da continuidade da linhagem imperial caracterizava-se como linha mestra das pesquisas, e a pré-história teria se tornado um campo seguro de investigação:

\section{the domain of organizing} archaeological evidence into nation-wide chronological systems, aided by the notion of stratigraphic excavation/observation and typology introduced in the second decade of the twentieth century [...] came to function as a kind of 'refuge' for archaeologists who were forced to conceal their political consciences and scientific observations and instead immersed themselves in the mechanistic, descriptive practice of constructing pottery typochronologies (Mizoguchi 2006: 70) ${ }^{1}$.

1 "o domínio de organizar evidência arqueológica em sistemas cronológicos de amplitude nacional, auxiliado pela noção de
Dessa forma, kaizuka é um elemento em meio a diversos outros elementos dentro da temática Jomon, a qual é situada em contraste à população do Paleolítico e principalmente à onda migratória que formou a população japonesa atual, com cerâmica dita Yayoi. Nesse sentido, discute-se o povoamento do arquipélago japonês, as diferentes culturas que habitaram o território e suas possíveis interações. A comparação com os Ainu e a população japonesa é foco dos debates da continuidade das populações pretéritas, também dentro da perspectiva de migração e mobilidade.

\section{Comparando cenários}

Em uma perspectiva comparada (Quadro 3), é possível situar sambaqui e kaizuka, enquanto vestígios arqueológicos em meio a questionamentos da arqueologia, dentro da esfera dos estudos de pré-história, problematizando tanto as evidências estudadas quanto o campo científico no qual são construídas.

Enquanto os kaizuka estão inseridos em mais de um período cultural delimitado e apresentam diversos vestígios, contribuindo para a caracterização do que tenha sido a ou as culturas Jomon, figurando como mais um dado, no Brasil, temos os sambaquis em si e a busca para delimitá-los, também diante das demais culturas com as quais tiveram contato ou vieram por habitar o mesmo local. A temática do povoamento do território mostra-se como um dos pontos de contato, uma vez que as ondas migratórias que adentraram o arquipélago japonês podem ter alguma relação com as ondas migratórias de entrada no continente americano, especialmente pelo Estreito de Bering.

escavação/observação estratigráfica e tipologia introduzida na segunda década do século $\chi \chi[\ldots]$ veio por funcionar como um tipo de 'refúgio' para arqueólogos, os quais eram forçados a esconder sua consciência política e observações científicas e, em vez disso, voltaram-se para a prática mecânica e descritiva de construção de cronologias por tipos de cerâmica" (tradução nossa). 


\begin{tabular}{|l|l|}
\hline \multicolumn{1}{|c|}{ Brasil } & \multicolumn{1}{c|}{ Japão } \\
\hline - $\begin{array}{l}\text { Povoamento do continente americano } \\
\text { - Caracterização da população sambaquieira, } \\
\text { cultura(s) e morfologia }\end{array}$ & $\bullet \begin{array}{l}\text { Povoamento do arquipélago japonês } \\
\text { Caracterização da população Jomon, cultura(s) e } \\
\text { morfologia }\end{array}$ \\
$\begin{array}{l}\text { Diferenciação entre populações (Lagoa Santa, } \\
\text { sambaquieiros e demais indigenas) }\end{array}$ & $\bullet \begin{array}{l}\text { Diferenciação e comparação com Yayoi, Ainu e } \\
\text { japoneses atuais }\end{array}$ \\
- $\begin{array}{l}\text { Migração e mobilidade (interior e litoral) } \\
\text { Sambaqui: sem cerâmica }\end{array}$ & $\begin{array}{l}\text { Migrac mobilidade (sazonalidade dos } \\
\text { assentamentos) } \\
\text { Kaizuka: com cerâmica }\end{array}$ \\
\hline
\end{tabular}

Quadro 3. Quadro comparativo de questões gerais que perpassam e norteiam as pesquisas sobre montes de conchas no Brasil e no Japão.

Fonte: Elaborado pelas autoras.

No tocante à caracterização das populações, outra interseção é a comparação de dados craniométricos entre séries Jomon e séries de Lagoa Santa (Neves 2014; Seguchi 2011). Tais investigações têm partido de métodos similares, porém com amostras diferentes. Todavia, o princípio das pesquisas é o mesmo, buscando um cladograma de forma a entender proximidades morfológicas entre populações, e, por conseguinte, entrever rotas migratórias e a dispersão de determinadas populações, também buscando debater se a entrada no continente americano foi um ou mais eventos. No arquipélago japonês não há dúvida em relação a pelo menos duas grandes migrações, uma que deu origem à população Jomon e outra posterior, proveniente da península coreana, dando origem ao que viria a ser a população japonesa.

A temática de distinção entre populações se mostra com diferentes nuances. No caso brasileiro, a caracterização de sambaquieiros é feita perante outras populações indígenas contemporâneas e posteriores, em perspectivas sincrônicas e diacrônicas, buscando aproximar ou distinguir populações em um mesmo momento, e buscando linhagens e heranças ao longo do tempo. No Japão, a caracterização é feita em contraste a populações de períodos distintos, diferenciando ondas migratórias e buscando um marco divisor entre Jomon e Yayoi, e se o encontro entre as populações foi pacífico ou hostil, com assimilação ou eliminação.
Outro diferencial dentro dessa temática é o envolvimento identitário, uma vez que, no imaginário social japonês, a população Yayoi é localizada como o início da sociedade japonesa. A população Jomon, tal qual os Ainu e as populações indígenas no Brasil, são caracterizados como "o outro", na esfera da alteridade que delineia oposta à identidade.

A presença de cerâmica em sambaquis é vista, em geral, como evidência de ocupações posteriores por outros grupos nas regiões Sul e Sudeste, mas na região Norte é por vezes entendida como um dado cultural e evidência do grupo que construiu tais sambaquis. No Japão, a presença de cerâmica é essencial para a caracterização dos sítios como Jomon, principalmente como dado cultural de identidade e como marco cronológico a fim de datar camadas e ocupações.

A sazonalidade continua como tema no Japão, em geral entendendo a pesca como atividade realizada principalmente no verão, e a caça no inverno. No Brasil, o caráter sazonal foi discutido no século XIX com perspectivas díspares, alguns apontando pesca no verão (Penna 1876), outros no inverno, escapando do vento invernal no planalto (Netto 1876) - e ainda é discutido em alguns casos.

Destarte, existem diversos pontos similares de questionamento que regem as investigações sobre sambaqui e kaizuka. O entorno que as cerca denota questionamentos acadêmicos com impactos políticos e sociais, e buscar traçar o povoamento dos territórios é 
parte da construção de identidades e narrativas. A antiguidade e a origem são elementos de legitimação presentes nos debates sobre a ocupação moderna diante das populações indígenas. Os elementos listados indicam o potencial conflituoso no qual estudos de sambaqui e kaizuka estão inseridos. Mesmo se uma pesquisa não tiver como fim responder ou contribuir com um desses questionamentos, estará fazendo-o de qualquer forma.

\section{REIS, S.; RODRIGUES-CARVALHO, C. Heaps of shells: situating artificial mounds of shells in Brazilian and Japanese prehistorical studies. R. Museu Arq. Etn., 28: 124-132,} 2017.

Abstract: Archaeological sites marked by visible presence of shells can be found in different regions around the world. Named for their most visible characteristic, in Brazil they are known as sambaqui and in Japan as kaizuka. Shell mounds studies are part of local, regional and global research. Therefore, we aimed to situated shell mound studies among such research and questioning, and in a comparative perspective, we analyzed to what extent such studies are inserted into investigative lines that promote a global dialogue.

Keywords: Sambaqui; Kaizuka; Brazilian Archaeology; Japanese Archaeology.

\section{Referências bibliográficas}

Bandeira, A.M. 2006. O povoamento da América visto a partir dos sambaquis do litoral equatorial amazônico do Brasil. Fumdhamentos, 7: 430-468.

Calippo, F.R. 2010. Sociedade sambaquieira, comunidades marítimas. Tese de doutorado. Programa de Pós-Graduação em Arqueologia, Museu de Arqueologia e Etnologia, Universidade de São Paulo, São Paulo.

Gaspar, M.D. 2004. Sambaqui: arqueologia do litoral brasileiro. Jorge Zahar, Rio de Janeiro.

Habu, J. 2004. Ancient Jōmon of Japan. Cambridge University Press, Cambridge.

Hudson, M.J. 2005. For the people, by the people: postwar Japanese archaeology and the Early Paleolithic hoax. Anthropological Science, 113 (2): 131-139.

Imamura, K. 1996. Prehistoric Japan: new perspectives on insular East Asia. University of Hawai'i Press, Honolulu.
Imamura, K. 2000a. Archaeological Research of the Jomon Period in the 21st Century. In: Sakamura, K., (Ed.), Digital Museum 2000: memory of Jōmon Period. Disponível em: <https://goo.gl/eGXQYc >. Acesso em: 09/01/2018.

Imamura, K. 2000b. Collections of Morse from the Shell Mounds of Omori. In: Sakamura, K., (Ed.), Digital Museum 2000: memory of Jōmon Period. Disponível em: $<$ https://goo.gl/38DyvV $>$. Acesso em: 09/01/2018.

Kobayashi, T. 2004. Jōmon reflections: forager life and culture in the prehistoric Japanese archipelago. Oxbow Books, Oxford.

Loureiro, A.G. 2003. Os aterros (cerritos) na fronteira Brasil - Uruguai: uma abordagem histórica e teórico-conceitual. Techné, (8): 105-113.

Matsu'ura, S.; Kondo, M. 2011. Relative chronology of the Minatogawa and the Upper Minatogawa series of human remains from Okinawa Island, Japan. Anthropological Science, 119(2): 173-182. 
Conchas aos montes: situando os montes artificiais de conchas nos estudos da pré-história brasileira e japonesa

R. Museu Arq. Etn., 28: 124-132, 2017.

Mizoguchi, K. 2002. An archaeological history of Japan: 30.000 B.C. to A.D. 700. University of Pennsylvania Press, Philadelphia.

Mizoguchi, K. 2006. Archaeology, society and identity in Modern Japan. Cambridge University Press, Cambridge.

Morse, E.S. 1877. Traces of early man in Japan. Nature, 17: 89

Morse, E.S. 1879. Shell-Mounds of Ōmori. Memoirs of the Science Department, 1 (1): 61-63.

Neves, W. et al. 2014. Morfologia craniana dos remanescentes ósseos humanos da Lapa do Santo, Lagoa Santa, Minas Gerais, Brasil: implicações para o povoamento das Américas. Boletim do Museu Paraense Emílio Goeldi, 9 (3): 715-740.

Prous, A. 1992. Arqueologia brasileira. Editora Universidade de Brasília, Brasília.

Raghavan, M. et al. 2015. Genomic evidence for the Pleistocene and recent population history of Native Americans. Science, 349 (6250): aab3884.

Romey, K.M. 2001. “God's hands” did the Devil's work. Archaeology 54 (1). Disponível em: <https:// goo.gl/N9Cu75>. Acesso em: 09/01/2018.

Sasaki, C.; Iijima, I. 1880. Jōshū Okadaira kaikyo hōkoku. Gakugei Shirin, 6 (31): 91-110.
Schiavetto, S. 2005. A questão étnica do discurso arqueológico: afirmação de uma identidade indígena minoritária ou inserção na identidade nacional? In: Funari, P.P.; Orser, C.; Schiavetto, S. Identidades, discurso e poder: estudos da arqueologia contemporânea. Fapesp, São Paulo, 77-90.

Seguchi, N. et al. 2011. An alternative view of the peopling of South America: Lagoa Santa in craniometric perspective. Anthropological Science 119 (1): 21-38.

Skoglund, P. et al. 2015. Genetic evidence for two founding populations of the Americas. Nature, 525: 104-108.

Wesolowski, V. et al. 2007. Grânulos de amido e fitólitos em cálculos dentários humanos: contribuição ao estudo do modo de vida e subsistência de grupos sambaquianos do litoral sul do Brasil. Revista do Museu de Arqueologia e Etnologia, 17: 191-210.

Yamaguchi, B. 1990. The hand bones of the Jōmon remains from the Ebishima (Kaitori) Shell Mound in Hanaizumi, Iwate Prefecture. Bulletin of the National Science Museum, series D, (16): 31-38.

Yamaguchi, B. 1991. The foot bones of the Jōmon remains from the Ebishima (Kaitori) Shell Mound in Hanaizumi, Iwate Prefecture. Bulletin of the National Science Museum, series D, (17): 9-19. 